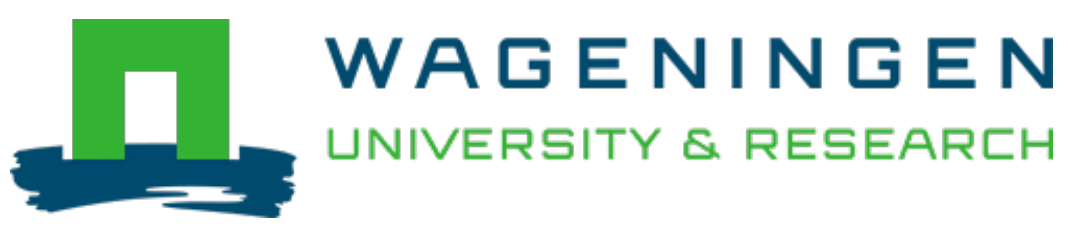

\title{
An antifungal compound produced by Bacillus subtilis YM 10-20 inhibits germination of Penicillium roqueforti conidiospores
}

\author{
Journal of Applied Microbiology \\ Chitarra, G.S.; Breeuwer, P.; Nout, M.J.R.; Aelst, A.C.; Rombouts, F.M. et al \\ https://doi.org/10.1046/j.1365-2672.2003.01819.x
}

This publication is made publicly available in the institutional repository of Wageningen University and Research, under the terms of article $25 \mathrm{fa}$ of the Dutch Copyright Act, also known as the Amendment Taverne. This has been done with explicit consent by the author.

Article 25 fa states that the author of a short scientific work funded either wholly or partially by Dutch public funds is entitled to make that work publicly available for no consideration following a reasonable period of time after the work was first published, provided that clear reference is made to the source of the first publication of the work.

This publication is distributed under The Association of Universities in the Netherlands (VSNU) 'Article $25 \mathrm{fa}$ implementation' project. In this project research outputs of researchers employed by Dutch Universities that comply with the legal requirements of Article $25 \mathrm{fa}$ of the Dutch Copyright Act are distributed online and free of cost or other barriers in institutional repositories. Research outputs are distributed six months after their first online publication in the original published version and with proper attribution to the source of the original publication.

You are permitted to download and use the publication for personal purposes. All rights remain with the author(s) and / or copyright owner(s) of this work. Any use of the publication or parts of it other than authorised under article $25 \mathrm{fa}$ of the Dutch Copyright act is prohibited. Wageningen University \& Research and the author(s) of this publication shall not be held responsible or liable for any damages resulting from your (re)use of this publication.

For questions regarding the public availability of this publication please contact openscience.library@wur.nl 


\title{
An antifungal compound produced by Bacillus subtilis YM 10-20 inhibits germination of Penicillium roqueforti conidiospores
}

\author{
G.S. Chitarra ${ }^{1}$, P. Breeuwer ${ }^{1}$ *, M.J.R. Nout ${ }^{1}$, A.C. van Aelst ${ }^{2}$, F.M. Rombouts ${ }^{1}$ and T. Abee ${ }^{1}$ \\ ${ }^{1}$ Department of Agrotechnology and Food Sciences, Laboratory of Food Microbiology, and ${ }^{2}$ Department of Plant Sciences, Laboratory \\ of Plant Cell Biology, Wageningen University, the Netherlands
}

2002/114: received 18 March 2002, revised 11 September 2002 and accepted 17 September 2002

\section{ABSTRACT

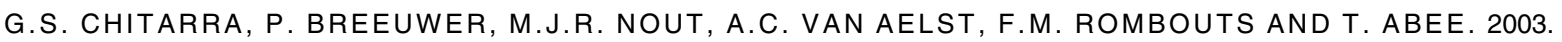

Aims: To identify and characterize an antifungal compound produced by Bacillus subtilis YM 10-20 which prevents spore germination of Penicillium roqueforti.

Methods and Results: The antifungal compound was isolated by acid precipitation with HCl. This compound inhibited fungal germination and growth. Identification by HPLC and mass spectrometry analysis showed high similarity to iturin A. Permeabilization and morphological changes in $P$. roqueforti conidia in the presence of the inhibitor were revealed by fluorescence staining and SEM, respectively.

Conclusions: The iturin-like compound produced by B. subtilis YM 10-20 permeabilizes fungal spores and blocks germination.

Significance and Impact of the Study: Fluorescence staining in combination with flow cytometry and scanning electron microscopy are efficient tools for assessing the action of antifungal compounds against spores. Iturin-like compounds may permeabilize fungal spores and inhibit their germination.

Keywords: antifungal, Bacillus subtilis, germination, inhibition, lipopeptides, spores.

\section{INTRODUCTION}

Penicillium roqueforti is a common fungal contaminant of bakery and silage products. It may produce several mycotoxins, such as roquefortine $\mathrm{C}$, isofumigaclavine $\mathrm{A}$ and $\mathrm{B}$, PR toxin and mycophenolic acid, which can cause economic losses and may affect human health (Samson et al. 1995).

The approaches that have been used to control fungal contamination in food are usually based on heat treatment or chemical treatment (Samson et al. 1995; Pitt and Hoching 1997). The antifungal food additives commonly used as preservatives are inorganic compounds, e.g. sulphite and nitrite, or weak organic acids, such as acetic, propionic,

\footnotetext{
Correspondence to: T. Abee, Department of Agrotechnology and Food Sciences, Wageningen University, PO Box 8129, 6700 EV Wageningen, The Netherlands (e-mail:Tjakko.Abee@micro.fdsci.mag-ur.nl).

*Present address: Nestlé Research Center, Food Quality and Safety, PO Box 44,

Vers-chez-Les-Blanc CH-1000 Lausanne, Smitzerland.
}

sorbic and benzoic acid (Kabara and Eklund 1991; Holyoak et al. 1996; Stratford and Anslow 1998). Alternatively, antifungal agents produced by micro-organisms may be used as biocontrol agents. In particular, Bacillus subtilis is known to produce a number of antifungal compounds including Alboleutin, Bacitracin, Botrycidin, Clorotetain, Fengycin, Iturins and Rhizocticins (Zuber et al. 1993). These antifungal peptides inhibit the growth of a large number of fungi, such as Aspergillus, Penicillium and Fusarium species (Munimbazi and Bullerman 1998), as well as yeasts, i.e. Candida albicans and Saccharomyces cerevisiae (Besson et al. 1979; Quentin et al. 1982; Latoud et al. 1990; Thimon et al. 1995). Whereas most of these antifungals have been tested against mycelial growth, very little information is available about their effect on fungal spore survival and germination.

Penicillium produces conidia as agents of reproduction, dispersal and/or survival. Conidia can survive for a long 
time under environmental stress, and outgrowth in food can result in food spoilage and, potentially, in the production of mycotoxins. Since germination is the starting event of the asexual life cycle of this fungus, the antifungal compounds should preferably prevent germination.

Microscopic assessment of germination has long been the standard method for determining the viability of fungal conidia. However, such germination assays are time-consuming. Fluorescence methods using probes such as carboxyfluorescein diacetate (cFDA) and propidium iodide (PI) have been used to evaluate conidial viability (Schading et al. 1995). cFDA is an enzyme activity probe that can pass through the membrane of the spores. Once inside the spores, it is cleaved by non-specific esterases to release the fluorescent carboxyfluorescein, which is retained inside the spores. Thus, viability can be correlated with the ability of the spores to accumulate carboxyfluorescein (Gahan 1984). PI is a nucleic acid probe that is supposed to cross only through damaged membranes in cells (Brul et al. 1997). Fluorescent labelling in combination with flow cytometry (FCM) allows fast measurement of individual cells for viability assessment (Brul 1997; Bunthof et al. 2001). Several methods have been developed using FCM to assess the effects of antibacterial agents on different cellular characteristics or parameters, including membrane permeability, membrane potential and respiration (Novo et al. 2000).

In this paper, the isolation, characterization and identification of an antifungal compound produced by Bacillus subtilis YM 10-20 is described. HPLC and mass spectrometry analysis revealed the compound to be similar to iturin A. Using fluorescence probes in combination with FCM, and using scanning electron microscopy (SEM), it is shown that this compound efficiently permeabilizes and disrupts fungal spores.

\section{MATERIALS AND METHODS}

\section{Bacterial culture}

Bacillus subtilis strain YM 10-20 (LU 1004 - NRRL B 23189), isolated from pre-harvest maize (Nout et al. 1997), was maintained on Plate Count Agar (PCA) slants and stored at $4^{\circ} \mathrm{C}$. The inoculum for production of antifungal compounds was prepared by growing the cells in brain heart infusion (BHI) medium on a rotary shaker at $130 \mathrm{rev} \mathrm{min}^{-1}$ at $30^{\circ} \mathrm{C}$ for $48 \mathrm{~h}$.

\section{Fungal suspension}

Penicillium roqueforti LU 510 was isolated from sugar beet press pulp (Nout et al. 1993) and was grown on malt extract agar medium (MEA; Oxoid) at $25^{\circ} \mathrm{C}$ for a maximum of 7 days. A spore suspension was prepared by adding $9 \mathrm{ml}$ peptone physiological salt solution $\left(8 \cdot 5 \mathrm{gl}^{-1} \mathrm{NaCl}\right.$ with $1 \mathrm{~g} \mathrm{l}{ }^{-1}$ bacteriological peptone (Oxoid) $+0 \cdot 1 \%$ Tween 80 ) to the agar slant. Subsequently, the suspension was filtered through a $17 \mu \mathrm{m}$ nylon filter, centrifuged twice at $4000 \mathrm{~g}$ for $3 \mathrm{~min}$, and the pellet containing the spores resuspended in malt extract broth (MEB) medium (Oxoid), adjusted to $\mathrm{pH} 4.0$ with lactic acid. The concentration of spores was determined using a haemocytometer and adjusted to $1 \cdot 0 \times 10^{6}$ conidia per $\mathrm{ml}$.

\section{Production and isolation of antifungal compounds from $B$. subtilis YM 10-20}

The method of Arrendale et al. (1988) with some modifications was used to extract the antifungal compound produced by $B$. subtilis strain YM 10-20. Bacillus subtilis cells grown in BHI were harvested after $48 \mathrm{~h}$ of incubation, final O.D. 600 approximately $3 \cdot 5$, and centrifuged at $4000 \mathrm{~g}$ for $15 \mathrm{~min}$ at $20^{\circ} \mathrm{C}$. The supernatant fluid was filtered through a sterile $0 \cdot 2 \mu \mathrm{m}$ poreny size filter. Subsequently, the $\mathrm{pH}$ of the supernatant fluid was adjusted to 2 with concentrated $\mathrm{HCl}$. After centrifugation at $16200 \mathrm{~g}$ for $10 \mathrm{~min}$ at $20^{\circ} \mathrm{C}$, the precipitate was collected and dissolved in methanol:water (50:50 v/v) $\mathrm{pH} 8$, filtered through $0.2 \mu \mathrm{m}$ membrane filter, and then stored at $-20^{\circ} \mathrm{C}$.

\section{Antifungal activity of $B$. subtilis YM 10-20}

The supernatant fluid of $B$. subtilis was tested for antagonistic activity against $P$. roqueforti, Aspergillus niger, A. parasiticus, A. flavus, Mucor sp., Fusarium culmorum and Rhizopus sp. Agar plates were prepared by mixing $50 \mathrm{ml}$ MEA medium with spore suspensions to obtain final concentration of $10^{4}$ spores per $\mathrm{ml}$ of each fungus. Two wells, $8 \mathrm{~mm}$ in diameter, were made in each plate; the bottom of the wells were sealed by filling with $80 \mu \mathrm{l} 2 \%$ bacteriological agar. Subsequently, the wells were filled with $200 \mu$ of $B$. subtilis strain YM 10-20 supernatant fluid or $\mathrm{HCl}$ precipitate suspended in methanol:water (50:50 $\mathrm{v} / \mathrm{v})$. The methanol:water $(50: 50 \mathrm{v} / \mathrm{v})$ solution was used as a control. The plates were incubated for 3 days at $30^{\circ} \mathrm{C}$ and subsequently, the diameter of the inhibition zone was measured. All experiments were carried out with two replicates per fungus.

\section{Germination test}

A volume of $500 \mu \mathrm{l}$ of the $P$. roqueforti LU 510 spore suspension of $1.0 \times 10^{6}$ conidia per $\mathrm{ml}$ was centrifuged, and the pellet containing the spores was resuspended in $500 \mu \mathrm{l}$ medium (MEB) $\mathrm{pH} 4$ in the presence of 10,25 and $50 \%$ of the supernatant fluid of B. subtilis YM 10-20. As a control, the pellet was resuspended in $500 \mu \mathrm{l}$ MEB with 
sterile distilled water $(50: 50 \mathrm{v} / \mathrm{v}) \mathrm{pH} 4$. After incubation at $25^{\circ} \mathrm{C}$ for $8 \mathrm{~h}, 100$ conidia of $P$. roqueforti were analysed with an Olympus Optical CO microscope at $1000 \times$ magnification (Ltda BX40, Tokyo, Japan) and the percentage of germinated conidia of each suspension was calculated. A conidium was considered germinated if the germ tube was longer than one-half of the diameter of the conidium. The $\mathrm{HCl}$ precipitate of $B$. subtilis was also used for the germination test at identical conditions and concentrations as those presented above. The experiment was performed in triplicate, and the results of a typical experiment are presented.

\section{Identification by HPLC and mass spectrometry analysis}

HPLC analysis was performed by injecting $50 \mu \mathrm{l}$ of the extracted material of $B$. subtilis on a Spherisorp ODS-2 column, $4.6 \mathrm{~mm} \times 250 \mathrm{~mm}$ (Chrompack, Bergen op Zoom, the Netherlands) and monitoring at 214 and $280 \mathrm{~nm}$. Elution $\left(0.9 \mathrm{ml} \mathrm{min}{ }^{-1}\right)$ was performed in a linear gradient in methanol:water $(50: 50 \mathrm{v} / \mathrm{v})$ during $0-20 \mathrm{~min}$, methanol:water $(80: 20 \mathrm{v} / \mathrm{v})$ during $20-60 \mathrm{~min}, 100 \%$ methanol during $60-65 \mathrm{~min}$ and methanol:water $(50: 50 \mathrm{v} / \mathrm{v})$ during 65-75 min. Individual fractions of the $\mathrm{HCl}$ precipitate of $B$. subtilis were collected manually and were subsequently tested for antagonistic activity against $P$. roqueforti as described previously. The mass spectrometry analysis was performed on a Perseptive Biosystems Voyager DE ${ }^{\mathrm{TM}}-\mathrm{RP}$ matrix assisted laser desorption/ionization (MALDI) Time of flight (TOF) (Basingstoke, UK) to determine the molecular weight of the compounds. Three matrices were applied in this study: sinapinic acid (proteins and peptides mol. wt $>10000 \mathrm{Da}), \alpha$-cyano-4 hydroxy cinnamic acid (proteins and peptides mol. wt $<10000 \mathrm{Da}$ ) and 2,4,6trihydroxiacetophenone (THAP) (peptides). Purified iturin A was kindly provided by Prof. Dr Françoise Peypoux (Laboratoire de Biochimie Analytique et Synthese Bioorganique, Lyon, France).

\section{Monitoring germination capacity}

The spore suspension of $P$. roqueforti at a concentration of $10^{6}$ spores per $\mathrm{ml}$ was incubated in the presence of $B$. subtilis supernatant fluid for 1,2 or $3 \mathrm{~h}$, and also in the presence of B. subtilis $\mathrm{HCl}$ precipitate for $2 \mathrm{~h}$. Subsequently, the spores were harvested by centrifugation at $2500 \mathrm{~g}$ for $3 \mathrm{~min}$. The pellet was washed in MEB and incubated for $10 \mathrm{~h}$. Each sample was observed every $2 \mathrm{~h}$ under the microscope to determine the percentage of spore germination. The control used in the $\mathrm{HCl}$ precipitate solution consisted of spores suspended in MEB medium with methanol and water $(50: 25: 25 \mathrm{v} / \mathrm{v} / \mathrm{v})$.

\section{SEM analysis}

Samples of fungal mycelium were removed from the border of the inhibition zone and transferred to a Nuclepore polycarbonate filter with $1 \mu \mathrm{m}$ pores (Costar, Cambridge, MA, USA). These filters are glued with Tissue Freezing Medium (Electron Microscopy Sciences, Washington D.C., USA) on a brass specimen holder. The specimens were frozen in liquid nitrogen and subsequently transferred to the cryo-preparation chamber (Oxford CT $1500 \mathrm{HF}$, Oxford Instruments, High Wycombe, UK), which was dedicated to FESEM. Inside the cryo-preparation chamber, the sample was kept for $3 \mathrm{~min}$ at $-95^{\circ} \mathrm{C}$ to sublime water contamination. The samples were coated at $-95^{\circ} \mathrm{C}$ with $5 \mathrm{~nm}$ platinum by magnetron sputtering and observed in an FESEM (JSM 6300F, Tokyo, Japan) at $-180^{\circ} \mathrm{C}$ and $5 \mathrm{kV}$. Digital images were recorded.

\section{Fluorescence of conidiospores}

The fluorescent probes, cFDA and PI (Molecular Probes, Eugene, OR, USA) were applied to assess the viability of $P$. roqueforti conidiospores. Spores were labelled with cFDA and PI. A stock solution of cFDA was prepared in acetone $\left(4.6 \mathrm{mg} \mathrm{ml}{ }^{-1}\right)$ and stored at $-20^{\circ} \mathrm{C}$ in the dark. A stock solution of PI $\left(1.0 \mathrm{mg} \mathrm{ml}^{-1}\right)$ was prepared in distilled water and stored in the refrigerator. Conidiospores of $P$. roqueforti LU 510 at a concentration of $10^{6}$ spores per $\mathrm{ml}$ were incubated for $2 \mathrm{~h}$ in the absence and presence of $1.0 \mathrm{ml}$ of $\mathrm{HCl}$ precipitate of $B$. subtilis YM 10-20. Samples containing $1.0 \mathrm{ml}$ of spore suspension of $P$. roqueforti were incubated with cFDA and PI at a final concentration of $10 \mu \mathrm{mol}^{-1}$. The samples were incubated for $15 \mathrm{~min}$ at $25^{\circ} \mathrm{C}$ and subsequently, the staining of the conidiospores was determined microscopically. The Axioskop epifluorescence microscope (Carl Zeiss, Oberkochen, Germany) was equipped with a $50 \mathrm{~W}$ mercury arc lamp, a fluorescein isothiocyanate filter set (excitation wavelength of 450 $490 \mathrm{~nm}$, emission wavelength $>520 \mathrm{~nm}$ ) and a Plan-Neofluar objective lens.

\section{FCM analysis}

Analysis of individual cells was performed with a FACSCalibur flow cytometer (Becton Dickinson Immunocytometry Systems, San Jose, CA, USA) equipped with an air-cooled argon ion laser at $15 \mathrm{~mW}$ (excitation wavelenth $488 \mathrm{~nm}$ ). Conidiospores of $P$. roqueforti LU 510 at a concentration of $10^{7}$ spores per $\mathrm{ml}$ were incubated for $3 \mathrm{~h}$ in the absence and presence of $1.0 \mathrm{ml}$ of $\mathrm{HCl}$ precipitate of B. subtilis YM 10-20. Subsequently, samples were diluted to $10^{6}$ spores per $\mathrm{ml}$ in $50 \mathrm{mmol} \mathrm{l}^{-1} \mathrm{KP}_{\mathrm{i}}$ buffer $(\mathrm{pH} \mathrm{7 \cdot 0)}$ ) and delivered at a low flow. The instrument was set up to collect 
five parameters: forward scatter (FSC), side scatter (SSC) and three fluorescent signals. A band pass filter of $530 \mathrm{~nm}$ $(515-545 \mathrm{~nm})$ was used to collect the green fluorescence (FL-1), a band pass filter of $585 \mathrm{~nm}(564-606 \mathrm{~nm})$ was used to collect the yellow-orange fluorescence (FL-2) and a long pass filter of $670 \mathrm{~nm}$ was used to collect the red fluorescence (FL-3). FSC was collected with a diode detector. SSC and the three fluorescence signals were collected with photomultiplier tubes. All signals were collected using logarithmic amplifications. Data were analysed with the CELLQuest program (version 3.1f; Becton Dickinson) and the WinMDI program (version 2.8; Joseph Trotter, John Curtin School of Medical Research, Canberra, Australia). The sample analysis time was $1 \mathrm{~min}$ and approximately 5000 particles were analysed.

\section{RESULTS}

\section{Inhibition of germination and fungal growth}

The supernatant fluid of B. subtilis strain YM 10-20 inhibited growth of $P$. roqueforti, Aspergillus niger, A. parasiticus, A. flavus, Mucor sp. and F. culmorum, whereas growth of Rhizopus sp. was not affected. Analysis of the inhibition zone diameters revealed $F$. culmorum to be the most sensitive fungus, followed by $P$. roqueforti and $A$. niger (data not shown).

The germination efficiency of $P$. roquefort $i$ spores after $8 \mathrm{~h}$ of incubation in the absence of $B$. subtilis strain YM 10-20 supernatant fluid was $84 \%$ (Fig. 1). In the presence of 10,25 and $50 \%$ of supernatant fluid, the percentage of germination decreased to 7, 1 and $0 \%$, respectively.

Penicillium roqueforti was chosen as the model organism to test the inhibitory activity of the $\mathrm{HCl}$ precipitate of the

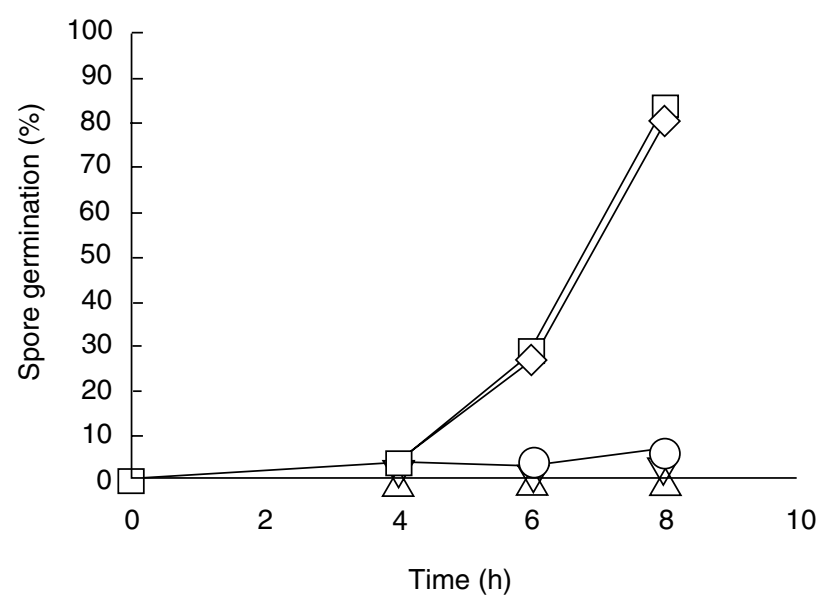

Fig. 1 Germination of Penicillium roqueforti in ( $\square$ ) malt extract broth $(\mathrm{MEB}),(\diamond) \mathrm{MEB} /$ distilled water $(50: 50 \mathrm{v} / \mathrm{v})$ and MEB containing $10 \%(\bigcirc), 25 \%(\nabla)$ and $50 \%(\triangle)$ of supernatant fluid of Bacillus subtilis YM 10-20
B. subitilis YM 10-20 supernatant fluid. The diameter of the inhibition zone of the $\mathrm{HCl}$ precipitate and that of the supernatant fluid was 25 and $17 \mathrm{~mm}$, respectively. The inhibitory zones remained the same for several days (data not shown).

\section{Effect of temperature and cholesterol on antifungal activity}

The antifungal compound produced by $B$. subtilis YM 10-20 was shown to be heat stable. After heat treatment at $70^{\circ} \mathrm{C}$ and $100^{\circ} \mathrm{C}$ for $1 \mathrm{~h}$, growth of $P$. roqueforti was still inhibited and the inhibitory zones were 18 and $8 \mathrm{~mm}$, respectively (data not shown). Furthermore, the antifungal compound was found to be resistant to proteolytic enzymes, including Pronase E, proteinase $K$ and $\alpha$ chymotrypsin (data not shown).

The antifungal activity was also tested in the presence of cholesterol (Sigma). After $9 \mathrm{~h}$ of incubation, the percentage of spore germination of $P$. roqueforti in the control (MEB:water [50:50 v/v]) was 90\%, whereas it was completely inhibited in the presence of the antifungal compound (MEB:supernatant fluid [50:50 v/v]). However, addition of cholesterol $\left(15 \mu \mathrm{g} \mathrm{ml}^{-1}\right)$ resulted in the latter case in $61 \%$ of spore germination, which points to a significant reduction of the antifungal activity under these conditions. Germination of $P$. roqueforti in the control was not affected by cholesterol (data not shown).

\section{Identification of the $\mathrm{HCl}$ precipitate}

Analysis of the $\mathrm{HCl}$ precipitate by HPLC showed one fraction that produced a clear inhibition zone against growth of $P$. roqueforti. Comparison of the HPLC profile of the $\mathrm{HCl}$ precipitate of strain YM 10-20 with that of purified iturin A revealed similar retention times and peak heights (data not shown). The mass spectrum of the compound of $B$. subtilis YM 10-20 showed homologous molecular ion peaks differing by 14 mass units at $\mathrm{m} / \mathrm{z} 1029$ and 1043. Other homologous peaks were observed at 1068 and 1082. The difference of 22 mass units in the molecular ion peaks at $\mathrm{m} / \mathrm{z}$ 1046 and 1068, and peaks at 1060 and 1082, indicates the presence of salt, i.e. sodium ions. A difference of 17 mass units in the molecular ion peaks at $\mathrm{m} / \mathrm{z} 1029$ and 1046, and peaks at 1082 and 1098, was also found. Comparison of the mass spectrum of the $\mathrm{HCl}$ precipitate with that of purified iturin A showed identical molecular ion peaks $(1029,1043$, $1046,1060,1068,1074$ and 1082) (Fig. 2), from which it is concluded that the antifungal compound of $B$. subtilis strain ( $\mathrm{HCl}$ precipitate) is highly similar to iturin $\mathrm{A}$.

\section{SEM and fluorescent probes}

SEM analysis showed major damage of the hyphae and the spores of $P$. roqueforti in the presence of the $\mathrm{HCl}$ precipitate 
Fig. 2 Mass spectrometry analysis (MALDITOF) of iturin A (a) and the $\mathrm{HCl}$ precipitate of Bacillus subtilis YM 10-20 (b)
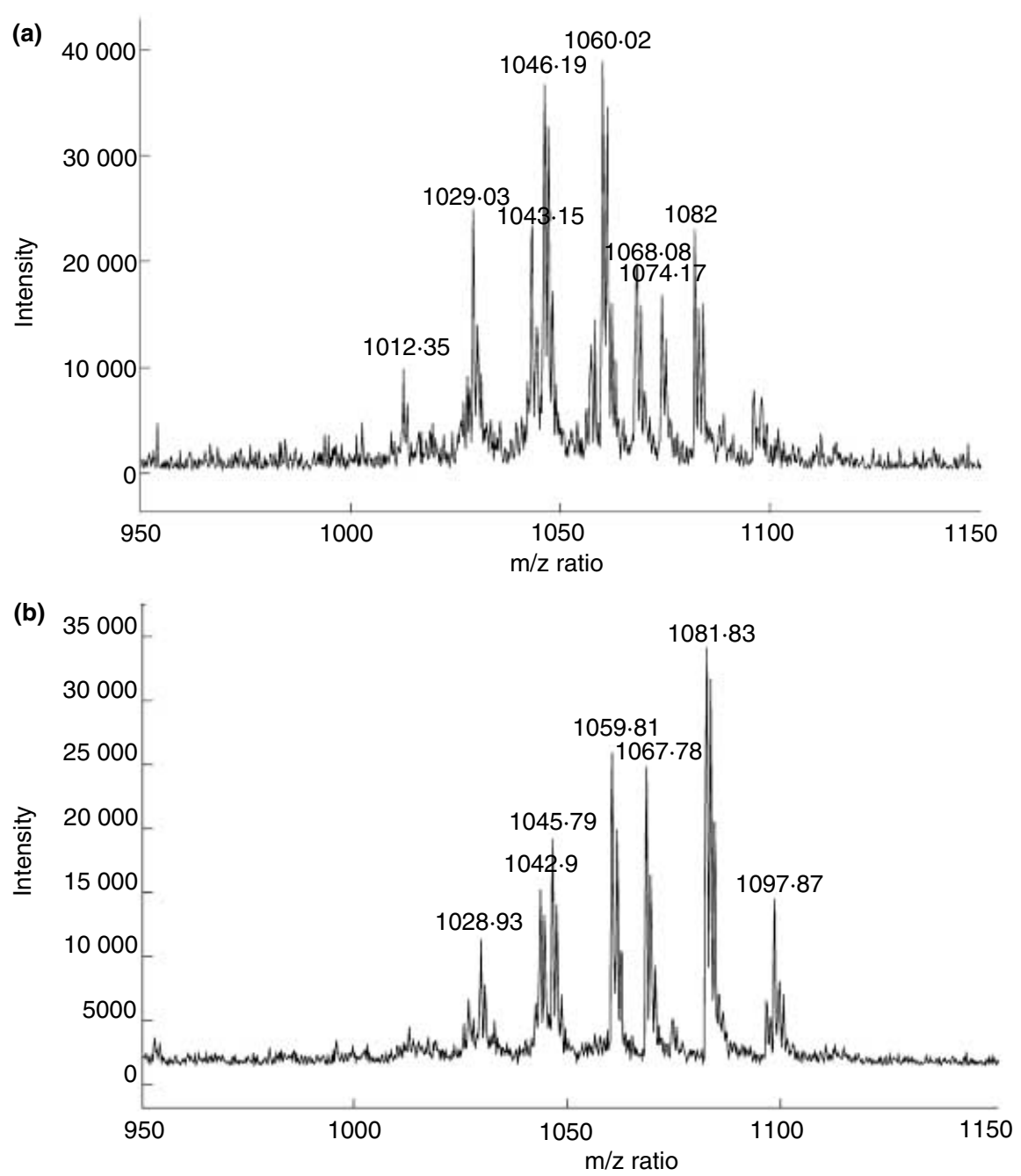

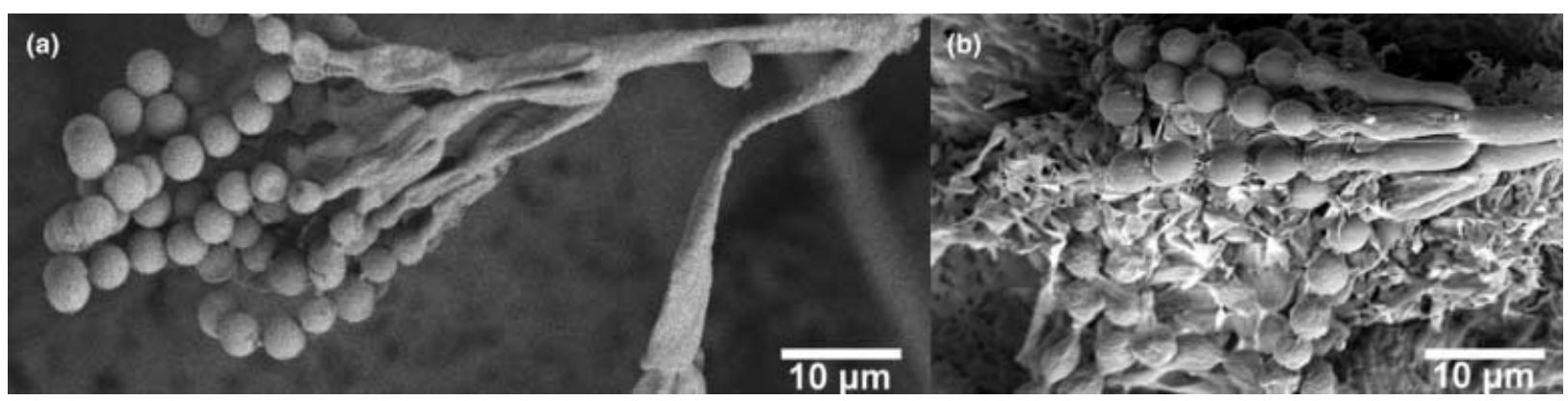

Fig. 3 Scanning electron microscopy of Penicillium roqueforti grown on malt extract agar in the absence (a) and presence (b) of Bacillus subtilis YM 10-20 supernatant fluid

(Fig. 3). Furthermore, germination of $P$. roqueforti was not observed after pre-incubation of the conidiospores with the $\mathrm{HCl}$ precipitate for $2 \mathrm{~h}$ followed by transfer to fresh MEB:methanol:water (50:25:25 v/v/v), suggesting irreversible damage of the conidiospores (data not shown).
To study the effect of the antifungal compound in more detail, fluorescent probes were applied to assess the membrane permeabilization and viability of the conidiospores of $P$. roqueforti. Untreated, control conidiospores could be stained with $\mathrm{cF}$, but not with PI. In contrast, conidiospores 
(a)

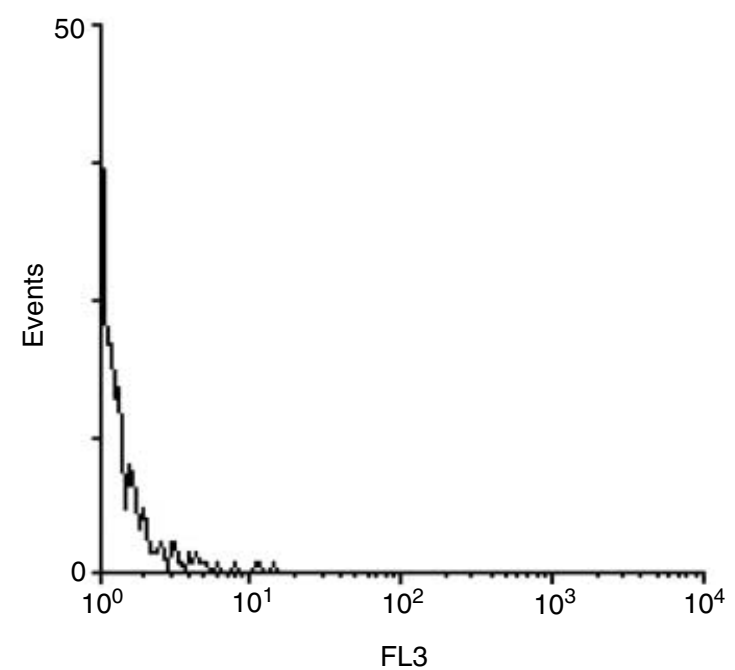

(b)

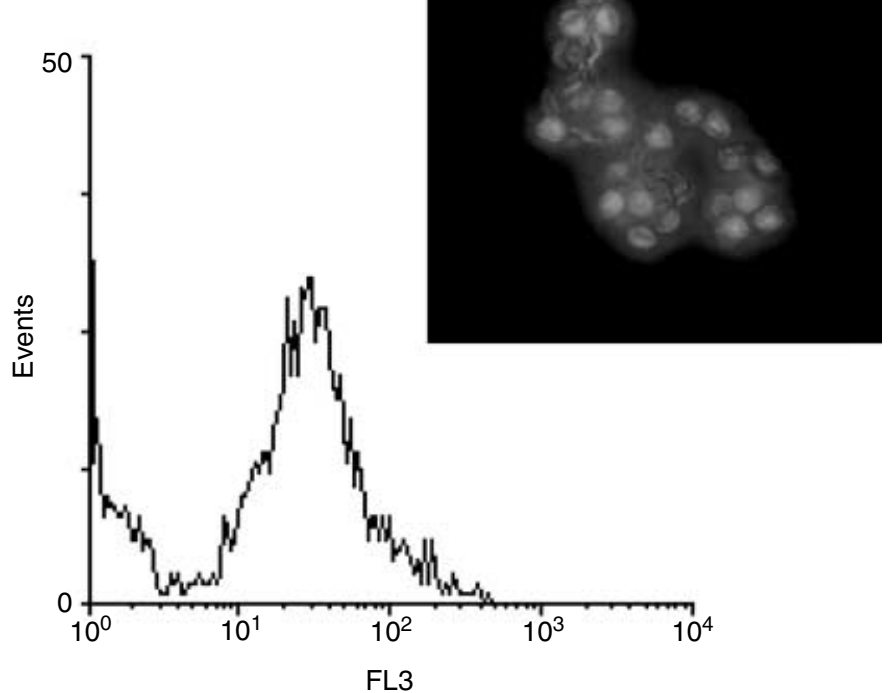

Fig. 4 Histograms of propidium iodide-stained control spores (a) and $\mathrm{HCl}$ precipitate-treated spores (b). The insert in (b) shows a fluorescence microscopy picture of PI-labelled spores.

treated with the $\mathrm{HCl}$ precipitate for $2 \mathrm{~h}$ could not be stained with $\mathrm{cF}$, whereas they were stained with PI. This indicates that the spores were permeabilized after treatment with the $\mathrm{HCl}$ precipitate. Indeed, FCM results show a distinct population of PI-labelled spores (Fig. 4).

\section{DISCUSSION}

In this study, the antifungal compound produced by B. subtilis YM 10-20 was shown to inhibit germination and growth of $P$. roqueforti conidiospores. The antifungal compound is very heat stable, its activity is reduced in the presence of cholesterol, and it is resistant to proteolytic degradation. These characteristics indicate that the antifungal compound may belong to the iturin group of antibiotics, which are known to interact with sterols of the cytoplasmic membrane of fungi (Maget-Dana et al. 1985, 1992; Latoud et al. 1990). Most of the known antifungal agents produced by $B$. subtilis are polypeptides (Babad et al. 1952; Besson et al. 1976; Pusey 1989; Munimbazi and Bullerman 1998), including iturins A-E, bacillomycins D, F and L, and mycosubtilin (Bland 1996). Recently, Moyne et al. (2001) described the antifungal action of two bacillomycin D variants. Iturins are cyclic lipopeptides characterized by the presence of seven $\alpha$-amino acids (Peypoux et al. 1973, 1978; Isogai et al. 1982; Latoud et al. 1990). Iturin A has been shown to increase the permeability of lipid membranes of fungal cells by pore formation, resulting in the loss of essential macromolecular compounds (Thimon et al. 1995).
HPLC analysis of the $\mathrm{HCl}$ precipitate from YM 10-20 showed that this compound is similar to iturin A. In addition, mass spectra analysis of the $B$. subtilis compound and of purified iturin $A$ revealed a high similarity between these compounds, i.e. identical molecular ion peaks were identified, suggesting that the compound produced by B. subtilis YM 10-20 is iturin A.

The $\mathrm{HCl}$ precipitate of strain $B$. subtilis YM 10-20 totally inhibited the germination of $P$. roqueforti conidiospores. SEM analysis of $P$. roqueforti conidiospores exposed to the $B$. subtilis supernatant fluid revealed destruction and morphology changes of spores. Germination of $P$. roqueforti was also inhibited in the presence of purified iturin A (data not shown). It appears that the $\mathrm{HCl}$ precipitate also affects the permeability of the membrane of conidiospores, preventing germination. Under these conditions, the spores will lose the ability to initiate biochemical activities, increase metabolism and initiate morphological changes. Notably, these studies reveal that the compounds may also act on spores.

Spore inactivation was also assessed by fluorescence techniques. Fluorescence microscopy and FCM revealed PI labelling of damaged cells, indicating permeabilization of the membrane of $P$. roqueforti conidiospores after exposure to the $\mathrm{HCl}$ precipitate. FCM analysis is a rapid, reliable and sensitive method for assessing viability (Roth et al. 1997; Novo 2000; Bunthof et al. 2001).

According to the present studies, the antifungal compound may be effective in the control of fungal growth. However, Rhizopus sp. was not sensitive (Pusey 1989). This may be explained by the low ergosterol content of the 
Rhizopus sp. membrane (Besson et al. 1979; Schnurer 1993).

In conclusion, fluorescence staining in combination with FCM and SEM are efficient tools for assessing the action of antifungal compounds against spores. Iturin-like compounds may permeabilize fungal spores and inhibit their germination. This is the first study to show that iturin-like compounds may permeabilize fungal spores and inhibit their germination.

\section{ACKNOWLEDGEMENTS}

The authors thank Edwin Bakx and Gert-Jan van Alebeek for technical assistance, and F. Peypoux for providing iturin A. They also thank Luiz G. Chitarra for critically reading the manuscript. This work was conducted with support of the Brazilian CAPES Coordenação de Aperfeiçoamento de Pessoal de Nível Superior.

\section{REFERENCES}

Arrendale, R.F., Gueldner, R.C., Chortyk, O.T. and Crumley, F.G. (1988) Characterization of the amino acids of antifungal peptides from $B$. subtilis by cold on-column injection capillary GC/MS Fournal of Microbiological Methods 8, 249-257.

Babad, J., Pinsky, A., Turner-Graff, R. and Sharon, N. (1952) An antifungal polypeptide produced by Bacillus subtilis. Nature 170, 618-619.

Besson, F., Peypoux, F., Michel, G. and Delcambe, L. (1976) Characterization of iturin $\mathrm{A}$ in antibiotics from various strains of Bacillus subtilis. Fapan Fournal of Antibiotics 29, 1043-1049.

Besson, F., Peypoux, F., Michel, G. and Delcambe, L. (1979) Antifungal activity upon Saccharomyces cerevisiae of iturin A, mycosubtilin, bacillomycin $\mathrm{L}$ and of their derivatives; inhibition of this antifungal activity by lipid antagonists. Fournal of Antibiotics 32, 828-833.

Bland, J.M. (1996) The first synthesis of a member of the iturin family, the antifungal cyclic lipopeptide, iturin-A2. Fournal of Organic Chemistry 61, 5663-5664.

Brul, S., Nussbaum, J. and Dielbandhoesing, S.K. (1997) Fluorescence probes for wall porosity and membrane integrity in filamentous fungi. Fournal of Microbiological Methods 28, 169-178.

Bunthof, C.J., Bloemen, K., Breeuwer, P., Rombouts, F.M. and Abee, T. (2001) Flow cytometric assessment of viability of lactic acid bacteria. Applied and Environmental Microbiology 67, 2326-2335.

Gahan, P.B. (1984) Plant Histochemistry and Cytochemistry. London: Academic Press.

Holyoak, C.D., Stratford, M., McMullin, Z., Cole, M.B., Crimmins, K., Brown, A.J.P. and Coote, J.P. (1996) Activity of the plasma membrane H+-ATPase and optimal glycolytic flux are required for rapid adaptation and growth of Saccharomyces cerevisiae in the presence of the weak-acid preservative sorbic acid. Applied and Environmental Microbiology 62, 3158-3164.

Isogai, A., Takayama, S., Murakoshi, S. and Suzuki, A. (1982) Structure of beta-amino acids in antibiotics iturin A screened for use against phytopathogenic fungi. Tetrahedron Letters 23, 3065-3068.
Kabara, J.J. and Eklund, T. (1991) Organic acids and esters. In Food Preservatives ed. Russell, N.J.G. pp. 45-71. New York, Glasgow and London: Blackie Academic and Professional.

Latoud, C., Peypoux, F. and Michel, G. (1990) Interaction of iturin A, a lipopeptide antibiotic, with Saccharomyces cerevisiae cells: influence of the sterol membrane composition. Canadian Fournal of Microbio$\log y$ 36, 384-389.

Maget-Dana, R., Thimon, L., Peypoux, F. and Ptak, M. (1992) Surfactin/iturin A interactions may explain the synergistic effect of surfactin on the biological properties of iturin A. Biochimie 74, 10471051.

Maget-Dana, R., Ptak, M., Peypoux, F. and Michel, G. (1985) Poreforming properties of iturin A, a lipopeptide antibiotic. Biochimica et Biophysica Acta 815, 405-409.

Moyne, A.L., Shelby, R., Cleveland, T.E. and Tuzun, S. (2001) Bacillomycin D: an iturin with antifungal activity against Aspergillus flavus. Fournal of Applied Microbiology 90, 622-629.

Munimbazi, C. and Bullerman, L.B. (1998) Isolation and partial characterization of antifungal metabolites of Bacillus pumilus. Fournal of Applied Microbiology 84, 959-968.

Nout, M.J.R., Bouwmeester, H.M., Haaksma, J. and Van Dijk, H. (1993) Fungal growth in silages of sugar beet press pulp and maize. Fournal of Agricultural Science 121, 323-326.

Nout, M.J.R., Platis, C.E. and Wicklow, D.T. (1997) Biodiversity of yeasts from Illinois maize. Canadian Fournal of Microbiology 43, 362367.

Novo, D.J., Perlmutter, N.G., Hunt, R.H. and Shapiro, H.M. (2000) Multiparameter flow cytometric analysis of antibiotic effects on membrane potential, membrane permeability, and bacterial counts of Staphylococcus aureus and Micrococus luteus. Antimicrobial Agents and Chemotherapy 44, 827-834.

Peypoux, F., Guinand, M., Michel, G., Delcambe, L., Das, B.C. and Lederer, E. (1978) Structure of iturine A, a peptidolipid antibiotic from Bacillus subtilis. Biochemistry 17, 3992-3996.

Peypoux, F., Guinand, M., Michel, G. et al. (1973) Isolement de l'acide 3-amino, 12-methyl teradecanoique et de l'acide 3-amino, 12-methyl tridecanoique a partir de l'iturine, antibiotique de Bacillus subtilis. Tetrahedron 29, 3455-3459.

Pitt, J.I. and Hoching, A.D. (1997) Fungi and Food Spoilage. London: Blackie Academic and Professional.

Pusey, P.L. (1989) Use of Bacillus subtilis and related organisms as biofungicides. Pesticide Science 27, 133-140.

Quentin, M.J., Besson, F., Peypoux, F. and Michel, G. (1982) Action of peptidolipidic antibiotics of the iturin group on erythrocytes: Effect of some lipids on hemolysis. Biochimica et Biophysica Acta 684, 207-211.

Roth, B.L., Poot, M., Yue, S.T. and Millard, P.J. (1997) Bacterial viability and antibiotic susceptibility testing with SYTOX green nucleic acid stain. Applied and Environmental Microbiology 63, 24212431.

Samson, R.A., Hoekstra, E.S., Frisvad, J.C. and Filtenborg, O. (1995) Introduction to Food-Borne Fungi. Baarn, the Netherlands: Centraalbureau voor Schimmelcultures.

Schading, R.L., Carruthers, R.I. and Mullin-Schading, B.A. (1995) Rapid determination of conidial viability for entomopathogenic hyphomycetes using fluorescence microscopy techniques. Biochemical Sciences and Technology 5, 201-208. 
Schnurer, J. (1993) Comparison of methods for estimating the biomass of three food-borne fungi with different growth patterns. Applied and Environmental Microbiology 59, 552-555.

Stratford, M. and Anslow, P.A. (1998) Evidence that sorbic acid does not inhibit yeast as a classic weak acid preservative. Letters in Applied Microbiology 27, 203-206.

Thimon, L., Peypoux, F., Wallach, J. and Michel, G. (1995) Effect of the lipopeptide antibiotic, iturin A, on morphology and membrane ultrastructure of yeast cells. FEMS Microbiology Letters 128, 101106.

Zuber, P., Nakano, M.M. and Marahiel, M.A. (1993) Peptide Antibiotics. In Bacillus subtilis and Other Gram-Positive Bacteria: Biochemistry, Physiology, and Molecular Genetics ed. Sonenshein, A.L., Hoch, J.A and Losick, R. pp. 897-916. Washington, D.C.: American Society for Microbiology. 